\title{
On the Estimation of Catch Efficiency of Sweeping Trammel Net*
}

\author{
Kô Matuda and Takeru Kitahara** \\ (Received September 4, 1967)
}

In a previous paper ${ }^{11}$, it was reported that the catch of the branquillos, Branchiostegus japonicus japonicus per unit operation in the sweeping trammel net fishery is approximately proportional to $1 / 3$ powers of the power of the engine from the analysis of the statistical data of the same gear from 1961 to 1965 in Wakasa Region of Fukui Prefecture.

The present paper contains the discussion on the estimation of the catch efficiency of this gear by using the relation

$$
q^{\prime}=k_{4} t \sqrt[3]{l^{2} P / h}
$$

ascertained in the previous paper and the efficiency of the gear estimated by KITAHARA and MATUDA ${ }^{2)}$. In Eq. (1) $q^{\prime}$ is the swept area per unit operation, $t$ the duration of towing, $l$ the length of the net, $P$ the power of the engine, $h$ the depth of the net and $k_{4}$ a constant.

The data adopted in the present paper are the same as that in the previous paper.

\section{Methods}

In the population dynamics of fish stocks, it is defined that the ratio of the catch per unit of effort $c$ to the stock $N$ which inhabit within the area $A$ of the fishing ground is equal to the ratio of the catchability coefficient $q$ to the area $A$, which is usually called the efficiency of gear especially by fishery scientists in Japan, and is denoted by $\alpha$;

$$
\frac{c}{N}=\frac{q}{A} \equiv \alpha
$$

Here, the catchability coefficient $q$ also implies the swept area per unit effort. This, strictly speaking, does not always represent the area swept actually by unit effort, but the area so as to be necessary for obtaining the amount of catch $c$ by unit effort if the density of school is uniform throughout the ground. Assuming that there is the following relation between the apparent swept area $q$ and the actual one $q^{\prime}$.

$$
q=k q^{\prime}
$$

* An outline of this article was presented to the autumn meeting of the Japanese Society of Scientific Fisheries, Fukuyama, October, 1966.

** Department of Fisheries, University of Kyoto, Maizuru. (松田 晈 - 北原 武：京都大学水産 学教空) 
where by $k$ is meant the ratio of the catch per unit effort to the amount of the sought species which inhabit in the area swept. This value $k$ may vary with the gear or the operation, so that it should be termed the catch efficiency of the gear.

In the present study, for the branquillos of the sweeping trammel net fishery in Wakasa Bay, this value $k$ may be estimated by means of Eq. (3) using $q^{\prime}$ calculated by Eq. (1) and $q$ by the other method as mentioned later. In this case, this value is expressed as the average from 1961 to 1965 , and the procedure of its estimation is described in the following.

According to MATUDA et al. ${ }^{3)}$ the constant $k_{4}$ in this equation takes approximately the value $0.62\left(\mathrm{~m}^{5 / 8} \mathrm{sec}^{-1}\right.$ h.p. $\left.{ }^{-1 / 3}\right)$. Since it seems that the present circumstances are almost similar to that in the field experiment, this value may be applicable to the present case. Then, as mentioned above, it was ascertained in the previous paper that both the gear and the operation are approximately independent of the power of the engine, so that we have the values obtained there, i.e. $l=268 \mathrm{~m}, h=2.0 \mathrm{~m}$, and $t=2.0$ hours. Therefore the swept area per unit operation is given by

$$
q^{\prime}=0.147 P^{1 / 3}\left(\mathrm{~km}^{2}\right) \text {. }
$$

From this relation, the weighted mean swept area $q^{\prime}$ per unit operation is calculated with weighting factor, i.e. the number of operation, and then we obtain $q^{\prime}=0.300 \mathrm{~km}^{2}$ per operation.

On the other hand, Kitahara et al. ${ }^{2)}$ have estimated the value of $\alpha$ on the basis of the same data as the present study by means of the DELURY's method ${ }^{4}$, in which it is determined from the decrease of the catch per unit effort with the increase of the amount of effort for each fishing season. However those thus obtained were the gear efficiency per unit boat-day. Then these values are converted into those per unit operation by dividing by the mean number of daily operation for the corresponding season. Then the average from 1961 to 1965 for the value thus obtained gives $\alpha=1.95 \times 10^{-4}$ per operation, as shown in Table 1 .

From Eq. (2), multiplying the value $\alpha$ thus obtained by the area of the fishing ground, i.e. $A=687 \mathrm{~km}^{2}$, we have the catchability coefficient $q=0.134 \mathrm{~km}^{2}$ per operation.

Table 1.

\begin{tabular}{c|c|c|c}
\hline \hline Year & Mean daily operation* & $\begin{array}{c}\text { Gear efficiency per } \\
\text { unit boat-day** }\end{array}$ & $\begin{array}{c}\text { Gear efficiency per } \\
\text { unit operation }\end{array}$ \\
\hline 1961 & 1.93 & $3.8 \times 10^{-4}$ & $1.97 \times 10^{-4}$ \\
1962 & 1.94 & $4.1 \times 10^{-4}$ & $2.12 \times 10^{-4}$ \\
1963 & 1.94 & $3.6 \times 10^{-4}$ & $1.86 \times 10^{-4}$ \\
1964 & 1.73 & $3.3 \times 10^{-4}$ & $1.91 \times 10^{-4}$ \\
1965 & 1.75 & $3.3 \times 10^{-4}$ & $1.89 \times 10^{-4}$ \\
\hline
\end{tabular}




\section{Results and Discussion}

Substituting the values $q^{\prime}$ and $q$ thus obtained into Eq. (3), we obtain the mean catch efficiency for the branquillos fishing of the sweeping trammel net in Wakasa Bay from 1961 to 1965 , that is $k=0.447$.

It is essential from the definition that $0 \leqq k \leqq 1$. In addition, in the case of the present study, it is expected to take the reasonably large value within the above limits, in view of the fact that this fishery is remarkably efficient for the branquillos compared with the other fisheries sought the same species. It seems that the value obtained here satisfies these conditions. It follows from this that in Wakasa Bay this gear has succeeded to catch approximately $45 \%$ of the branquillos inhabited in the area swept by a single operation.

The value of the catch efficiency may vary with various conditions; such as the mesh size, the sizes of the net, the boat, and the engine, the fishing technique, the species sought, their habit, etc. However, it seems that the value of $k$ above obtained is applicable to the other region where this gear has been used; such as Niigata, Ishikawa, Shimane and Ehime Prefectures, because the above conditions are almost similar to the present case. In cases in which of the above conditions the mesh size is largely varied, a great care must be paid in its application, since the mesh selection may affect the catch efficiency.

The authors are indebted to Prof. Tasae KAWAKaMI for suggesting this investigation as well as for constant guidance in this cource of the work.

\section{References}

1) K. Matuda: This Bull. 33, 1092-1095 (1967).

2) T. Kitahara, and K. Matuda: ibid, 33, 1087-1091 (1967).

3) K. MATUdA, and T. Kitahara: ibid., 33, 524-530 (1967).

4) D. B. DeLuRY: Biometrics, 3, 145-167 (1947). 